\title{
Vaccines for COVID-19 in patients with atopic dermatitis: three things every dermatologist should know
}

\author{
Federico Diotallevi ${ }^{1 \star}$, Oriana Simonetti ${ }^{1 凶 \star}$, Giulia Radi ${ }^{1}$, Elisa Molinelli ${ }^{1}$, Giulio Rizzetto ${ }^{1}$, Oscar Cirioni ${ }^{2}$, Marcello Mario
} D’Errico ${ }^{3}$, Annamaria Offidani ${ }^{1}$

${ }^{1}$ Dermatology Clinic, Department of Clinical and Molecular Sciences, Polytechnic University of Marche, Ancona, Italy. ${ }^{2}$ Infectious Diseases Clinic, Department of Biomedical Sciences and Public Health, Polytechnic University of Marche, Ancona, Italy. ${ }^{3}$ Department of Biomedical Sciences and Public Health, Section of Hygiene, Preventive Medicine, and Public Health, Polytechnic University of Marche, Ancona, Italy.

\begin{abstract}
Almost 13 months have passed since the World Health Organization (WHO) declared the coronavirus disease 19 (COVID-19) pandemic, caused by the SARS-CoV-2, on March 11th, 2020. During this period, we have realized that the most effective weapon we have to prevent SARS-CoV-2 infection, or to make it less aggressive, is vaccines. Currently, according to the WHO document "Draft landscape of COVID-19 candidate vaccines," there are 275 vaccines in development against the virus, although at the moment there are four preparations in distribution in the United States and in Europe. The characteristics of these vaccines are quite different from each other and may even be unfamiliar in the medical field. In particular, among dermatologists, knowledge of vaccines is of fundamental importance, especially in atopic dermatitis. Atopic patients are aware of having a predisposition to develop allergies, and so they are asking dermatologists about the safety of the vaccines currently available against the SARS-CoV-2. This article provides an up-to-date overview of this topic by reviewing current literature and sharing our personal experience.
\end{abstract}

Keywords: coronavirus, SARS-CoV-2, dermatology, atopic dermatitis, immunization

Received: 2 March 2021| Returned for modification: 19 April 2021| Accepted: 5 May 2021

\section{Introduction}

The most effective weapon we have to prevent SARS-CoV-2 infection, or to make it less aggressive, is vaccines. Currently, according to the document "Draft landscape of COVID-19 candidate vaccines," there are 275 vaccines in development against the virus, although there are currently three preparations authorized by both the Food and Drug Administration (FDA) and the European Medicines Agency (EMA) for emergency use, produced by PfizerBioNTech $^{\circledR}$, Moderna ${ }^{\circledR}$, and Janssen ${ }^{\circledR}$, respectively, and one preparation currently authorized only by the EMA, which is the vaccine produced by AstraZeneca ${ }^{\circledR}$ (1).

There is a strong emerging need to understand the crucial role of the vaccine for all clinicians, including dermatologists, who should focus attention on the need to vaccinate patients with atopic dermatitis (AD), considering vaccine timing with respect to therapies in progress in atopic patients. Atopic patients are aware that they have a predisposition to develop allergies, and so they are asking dermatologists whether safety information is available for the vaccines currently available against SARS-CoV-2 (2-3). This article briefly reviews three things that dermatologists should know about COVID-19 vaccines to be better prepared for managing $\mathrm{AD}$ patients.

\section{What are the characteristics of the vaccines available against SARS-CoV-2?}

The first two vaccines developed against COVID-19 currently authorized by the FDA and EMA are BNT162 (Comirnaty ${ }^{\circledR}$ ) and mRNA-1273, produced by Pfizer/BioNTech ${ }^{\circledR}$ and Moderna ${ }^{\circledR}$, respectively (Table 1). They consist of a lipid nanoparticle-formulated, nucleoside-modified RNA (modRNA) encoding the SARS-CoV-2 full-length spike, capable of eliciting high SARS-CoV-2 neutralizing antibody titers and robust antigen-specific CD8+ and Th1-type CD4+ T-cell responses (4-5).

The advantage of mRNA vaccines is that they are easily producible and have a low cost, but they require storage at low temperatures. In particular, the Pfizer vaccine requires storage at a temperature between $-60{ }^{\circ} \mathrm{C}$ and $-90{ }^{\circ} \mathrm{C}$, whereas the Moderna vaccine requires a storage temperature between $-25^{\circ} \mathrm{C}$ and $-15^{\circ} \mathrm{C}$. The storage temperature of the Moderna vaccine is therefore the temperature of a standard freezer, which is much more available than the ultra-cold deep freezers needed for storage of the Pfizer vaccine (6). According to data published by the two companies, the two vaccines seem to have an efficacy of about $95 \%(7,8)$.

The other two vaccines approved by both the FDA and the EMA, and by the FDA only, respectively, are Ad26.CoV2.S and AZD1222,

Table 1 | Features of the four vaccines against SARS-CoV-2 (1).

\begin{tabular}{|c|c|c|c|c|c|}
\hline $\begin{array}{l}\text { COVID-19 vaccine developer/ } \\
\text { manufacturer }\end{array}$ & Vaccine platform & $\begin{array}{c}\text { Type of candidate } \\
\text { vaccine }\end{array}$ & Number of doses & Timing of doses & $\begin{array}{c}\text { Route of } \\
\text { administration }\end{array}$ \\
\hline Moderna / NIAID & RNA & LNP-encapsulated mRNA & 2 & 28 days apart & Intramuscular \\
\hline BioNTech / Fosun Pharma / Pfizer & RNA & 3 LNP-mRNAs & 2 & 21 days apart & Intramuscular \\
\hline $\begin{array}{l}\text { Janssen Pharmaceutical } \\
\text { Companies }\end{array}$ & $\begin{array}{l}\text { Non-replicating } \\
\text { viral vector }\end{array}$ & $\begin{array}{c}\text { Adenovirus type } 26 \\
\text { vector }\end{array}$ & 1 & Single dose & Intramuscular \\
\hline University of Oxford / AstraZeneca & $\begin{array}{l}\text { Non-replicating } \\
\text { viral vector }\end{array}$ & $\begin{array}{l}\text { ChAdOx1-S or } \\
\text { AZD1222 }\end{array}$ & 2 & 4-12 weeks apart & Intramuscular \\
\hline
\end{tabular}

LNP = lipid nanoparticle. 
produced by Janssen Pharmaceutical Companies and the Universitiy of Oxford/AstraZeneca respectively (Table 1). These are "viral vector vaccines," and they work by providing cells with genetic instructions to make antigens. These vaccines are made from adenovirus vectors that have been genetically engineered so they cannot reproduce in the human body. They are also engineered to contain DNA sequences for the $\mathrm{S}$ protein. Once inside the vaccine recipient's cells, the DNA is transcribed into mRNA, which is then translated into a viral S protein just like the mRNA vaccines. Once this protein is produced, an immune response involving both innate and adaptive immunity is triggered, which can confer a certain level of protection from SARS-CoV-2 infection. Unlike mRNA vaccines, these two vaccines produced by Janssen and AstraZeneca do not need to be stored at extremely low temperatures but can be stored for at least 6 months in a refrigerator, at a temperature between 2 and $8{ }^{\circ} \mathrm{C}(9,10)$.

\section{Is it reasonable to believe that these vaccines can cause reactivation of eczema in subjects with atopic dermatitis?}

$\mathrm{AD}$ is an immune-mediated inflammatory disease of the skin with a chronic relapsing course that affects $20 \%$ of children and $10 \%$ of adults $(11,12)$. It is often accompanied by increased serum IgE levels and a personal and family history of "atopic diathesis," which includes type 1 allergies, allergic rhinitis, and asthma. The pathogenesis of the disease is extremely complex, with a multifactorial etiology involving genetic, immunologic, and environmental factors that result in disruption of the skin barrier and the skin immune system (12).

Vaccines currently available against SARS-CoV-2 are only targeted toward the adult population (the Pfizer vaccine is available for those 16 years and older). The population of phase III studies conducted on COVID-19 vaccines does not include children, although children play an active role in the COVID-19 pandemicnot so much as victims of the virus, but as vectors of viral transmission $(6-10,13)$.

When and if a vaccine is available for children, however, parents of atopic patients should be reassured that 1) it is not expected that common childhood vaccines promote atopic disease, and any future development of atopic symptoms is most likely not related to vaccination but is coincidental, and 2) vaccines that have been associated with a relapse of AD or complications (not without discussion), such as eczema vaccinatum, belong to the category of live attenuated vaccines, a category different from the vaccines currently available (14-15).

In addition, unlike seasonal influenza vaccines, the vaccines currently available against SARS-CoV-2 are not egg-based, and so there is no risk of allergic reactions in atopic adults and children in whom the prevalence of egg sensitization and allergy is higher (16).

Regarding the hypothesis that atopic subjects have a different immunization risk to SARS-CoV-2 vaccine than non-atopic subjects, no data are available in the literature. The only available data are related to the seasonal influenza vaccine. A study by Leung et al. showed that seroprotection rates for influenza $\mathrm{B}, \mathrm{H} 1 \mathrm{~N} 1$, and $\mathrm{H}_{3} \mathrm{~N}_{2}$ were not different i) between participants with and without $\mathrm{AD}$ receiving intradermal vaccination and ii) between participants with $\mathrm{AD}$ receiving intradermal and intramuscular vaccination, respectively (17). In addition, after intradermal but not after intramuscular vaccination, participants with AD colo- nized with Staphylococcus aureus exhibited a reduced immune response to influenza vaccination compared with noncolonized participants. Because the majority of patients with $\mathrm{AD}$ are colonized with $S$. aureus, the authors have argued that intramuscular influenza vaccination should be given preference in these patients (17-18). This is reassuring because SARS-CoV-2 vaccines are administered intramuscularly.

In conclusion, there are no data to support a warranted fear of vaccines against SARS-CoV-2 in atopic patients.

\section{Will atopic patients taking immunosuppressive drugs or dupilumab be able to receive the vaccine?}

Unfortunately, data on the efficacy or safety of vaccines against COVID-19 in patients affected by chronic inflammatory diseases on immunosuppressive therapy are not available because these patients are naturally excluded from clinical trials. The only data in this type of population that can be extrapolated from the literature refer to other types of vaccines, such as the seasonal influenza vaccine (19).

Corticosteroids and many disease-modifying anti-rheumatic drugs (DMARDs) may contribute to reduced vaccine immunogenicity (19). For example, treatment with prednisone $\geq 10 \mathrm{mg} /$ day equivalent doses have been shown to decrease humoral responses to influenza vaccines in patients with systemic lupus erythematosus (20). Likewise, methotrexate (MTX) reduced humoral responses to influenza and pneumococcal vaccines (21-23). To optimize the immunogenicity of inactivated vaccines in patients naive to immunosuppressive drug, Papp et al. suggested that immunization be performed, if possible, at least 2 weeks before the start of immunosuppressive therapy (19).

Because they do not belong to these categories of vaccines, the currently available vaccines for SARS-CoV-2 should not have this type of effect and are expected to be safe for patients on immunotherapeutics (20). It will be necessary to use a case-by-case approach to assess the risk-benefit ratio of a possible preventive discontinuation of immunosuppressive therapy before performing vaccination.

Dupilumab is a fully human monoclonal antibody that binds to the alpha subunit of the interleukin-4a (IL-4Ra) receptor, which inhibits both IL-4 and IL-13 signaling (24). Dupilumab has been shown to improve signs and symptoms of moderate-to-severe $\mathrm{AD}$, asthma, eosinophilic esophagitis, and chronic sinusitis with nasal polyposis, and it is approved in the European Union, the United States, Japan, and other countries for the treatment of adults with moderate to severe $\mathrm{AD}$ in whom topical therapies are not recommended or do not adequately control the disease (25).

In this case as well, the only available data are related to other vaccines. In particular, Blauvelt et al. have conducted a phase 2, randomized, double-blinded, multicenter, placebo-controlled, parallel-group study, with the aim of evaluating the effects of tetanus toxoid with reduced diphtheria toxoid and acellular pertussis vaccine (Tdap) and quadrivalent meningococcal polysaccharide vaccine (MPSV4) in adult patients receiving dupilumab. They concluded that non-live vaccines such as Tdap and MPSV 4 can be indicated as safe and are not immunogenic in adult patients with moderate to severe AD treated with dupilumab (26).

Because SARS-CoV-2 vaccines are mRNA or viral vector vaccines, there should be no additional risk in patients treated with dupilumab. 


\section{Conclusions}

Further study will be required to define the safety and efficacy of SARS-CoV-2 vaccines in vulnerable populations. However, with the current state of knowledge and following an extensive review of the literature presented, there are no contraindications to vaccinating people with $\mathrm{AD}$, either on immunosuppressive therapy or on dupilumab therapy.

\section{References}

1. World Health Organization. Draft landscape of COVID-19 candidate vaccines [Internet, updated 2021 April 20]. Available from: https://www.who.int/publications/m/item/draft-landscape-of-covid-19-candidate-vaccines.

2. Verschoor D, von Gunten S. Allergy and atopic diseases: an update on experimental evidence. Int Arch Allergy Immunol. 2019;180:235-43.

3. Radi G, Simonetti O, Diotallevi F, Campanati A, Brisigotti V, Molinelli E, et al. How can I take care of you? The dermatologist meets patients' needs during the COVID-19 pandemic. Dermatol Ther. 2020;33:e13740.

4. Pardi N, Tuyishime S, Muramatsu H, Kariko K, Mui BL, Tam YK, et al. Expression kinetics of nucleoside-modified mRNA delivered in lipid nanoparticles to mice by various routes. J Control Release. 2015;217:345-51.

5. Karikó K, Muramatsu H, Welsh FA, Ludwig J, Kato H, Akira S, et al. Incorporation of pseudouridine into mRNA yields superior nonimmunogenic vector with increased translational capacity and biological stability. Mol Ther. 2008;16:183340.

6. Krammer F. SARS-CoV-2 vaccines in development. Nature. 2020;586:516-27.

7. Polack FP, Thomas SJ, Kitchin N, Absalon J, Gurtman A, Lockhart S, et al. Safety and efficacy of the BNT162b2 mRNA Covid-19 vaccine. N Engl J Med. 2020; 383:2603-15.

8. Anderson EJ, Rouphael NG, Widge AT, Jackson LA, Roberts PC, Makhene M, et al. Safety and immunogenicity of SARS-CoV-2 mRNA-1273 vaccine in older adults. N Engl J Med. 2020;383:2427-38.

9. Voysey M, Clemens SAC, Madhi SA, Weckx LY, Folegatti PM, Aley PK, et al. Safety and efficacy of the ChAdOx1 nCoV-19 vaccine (AZD1222) against SARS-CoV-2: an interim analysis of four randomised controlled trials in Brazil, South Africa, and the UK. Lancet. 2021;397:99-111. Erratum in: Lancet. 2021;397:98.

10. A study of Ad26.COV2.S for the prevention of SARS-CoV-2-mediated COVID-19 in adult participants (ENSEMBLE) [Internet, updated 2021 April 14]. Available from: https://clinicaltrials.gov/ct2/show/NCTo4505722.

11. Weidinger S, Novak N. Atopic dermatitis. Lancet. 2016;387:1109-22.

12. Langan SM, Irvine AD, Weidinger S. Atopic dermatitis. Lancet. 2020;396:34560.

13. Simonetti O, Diotallevi F, Campanati A, Brisigotti V, Radi G, Molinelli E, et al. Global coronavirus pandemic (SARS-CoV-2): past, present, and future of pediatric dermatology. Dermatol Ther. 2020;33:e13767.

14. Grüber C. Childhood immunisations and the development of atopic disease. Arch Dis Child. 2005;90:553-5.
15. Reed JL, Scott DE, Bray M. Eczema vaccinatum. Clin Infect Dis. 2012;54:832-40. 16. Martorell A, Alonso E, Boné J, Echeverría L, López MC, Martín F, et al. Food Allergy Committee of SEICAP. Position document: IgE-mediated allergy to egg protein. Allergol Immunopathol (Madr). 2013;41:320-36.

17. Leung DYM, Jepson B, Beck LA, Hanifin JM, Schneider LC, Paller AS, et al. A clinical trial of intradermal and intramuscular seasonal influenza vaccination in patients with atopic dermatitis. J Allergy Clin Immunol. 2017;139:1575-82.e8.

18. Boguniewicz M, Leung DY. Atopic dermatitis: a disease of altered skin barrier and immune dysregulation. Immunol Rev. 2011;242:233-46.

19. Papp KA, Haraoui B, Kumar D, Marshall JK, Bissonnette R, Bitton A, et al. Vaccination guidelines for patients with immune-mediated disorders on immunosuppressive therapies. J Cutan Med Surg. 2019;23:50-74.

20. Gresham LM, Marzario B, Dutz J, Kirchhof MG. An evidence-based guide to SARS-CoV-2 vaccination of patients on immunotherapies in dermatology. J Am Acad Dermatol. 2021;84:1652-66

21. Crowe SR, Merrill JT, Vista ES, Dedeke AB, Thompson DM, Stewart S, et al. Influenza vaccination responses in human systemic lupus erythematosus: impact of clinical and demographic features. Arthritis Rheum. 2011;63:2396-406.

22. Ribeiro AC, Guedes LK, Moraes JC, Saad CG, Aikawa NE, Calich AL, et al. Reduced seroprotection after pandemic $\mathrm{H}_{1} \mathrm{~N}_{1}$ influenza adjuvant-free vaccination in patients with rheumatoid arthritis: implications for clinical practice. Ann Rheum Dis. 2011;70:2144-7.

23. Kapetanovic MC, Nagel J, Nordstrom I, Saxne T, Geborek P, Rudin A. Methotrexate reduces vaccine-specific immunoglobulin levels but not numbers of circulating antibody-producing B cells in rheumatoid arthritis after vaccination with a conjugate pneumococcal vaccine. Vaccine. 2017;35:903-8.

24. Beck LA, Thaçi D, Hamilton JD, Graham NM, Bieber T, Rocklin R, et al. Dupilumab treatment in adults with moderate-to-severe atopic dermatitis. N Engl J Med. 2014;371:130-9.

25. Fargnoli MC, Esposito M, Ferrucci S, Girolomoni G, Offidani A, Patrizi A, et al. A 48-week update of a multicentre real-life experience of dupilumab in adult patients with moderate-to-severe atopic dermatitis. J Dermatol Treat. 2020;1-4.

26. Blauvelt A, Simpson EL, Tyring SK, Purcell LA, Shumel B, Petro CD, et al. Dupilumab does not affect correlates of vaccine-induced immunity: a randomized, placebo-controlled trial in adults with moderate-to-severe atopic dermatitis. J Am Acad Dermatol. 2019;80:158-67.e1. 